\title{
Combination therapy with low dose sirolimus and tacrolimus is synergistic in preventing spontaneous and recurrent autoimmune diabetes in non-obese diabetic mice
}

\author{
A. M.J.Shapiro ${ }^{1}$, W.L.Suarez-Pinzon ${ }^{2}$, R.Power ${ }^{3}$, A. Rabinovitch ${ }^{2}$ \\ ${ }^{1}$ Department of Surgery, University of Alberta, Edmonton, Alberta, Canada \\ ${ }^{2}$ Heritage Medical Research Centre, Department of Medicine, University of Alberta, Edmonton, Alberta, Canada \\ ${ }^{3}$ Department of Laboratory Medicine and Pathology, University of Alberta, Edmonton, Alberta, Canada
}

\section{Abstract}

Aims/hypothesis. Sirolimus and tacrolimus are immunosuppressive drugs that prevent rejection of pancreatic islet allografts transplanted into patients with Type I (insulin-dependent) diabetes mellitus. This study aimed to determine whether sirolimus and tacrolimus can prevent autoimmune beta-cell destruction, and if so, what the mechanisms of action are.

Methods. Sirolimus and tacrolimus were given separately and together to female non-obese diabetic (NOD) mice from age 12 to 35 weeks. Diabetes incidence was determined and pancreatic insulitis and insulin content were measured. Sirolimus and tacrolimus were also given separately and together to diabetic NOD mice from the time of syngeneic islet transplantation until the reappearance of hyperglycaemia. Islet grafts were examined by RT-PCR assay for expression of interferon (IFN)- $\gamma$, interleukin (IL)-2, IL-4, IL-10 and transforming growth factor (TGF)- $\beta 1$.

Results. Low doses of sirolimus $(0.1 \mathrm{mg} / \mathrm{kg})$ and tacrolimus $(0.1 \mathrm{mg} / \mathrm{kg})$ were synergistic in reducing in- sulitis, preserving pancreatic insulin content and preventing diabetes in female NOD mice $(8 \%$ diabetes incidence at 35 weeks vs $66 \%$ in vehicle-treated mice). Also, the combination of sirolimus and tacrolimus prolonged syngeneic islet graft survival (median 34 days vs 13 days for vehicle-treated mice). Islet grafts from sirolimus plus tacrolimus-treated mice expressed significantly decreased mRNA contents of Th1-type cytokines (IFN- $\gamma$ and IL-2) and the highest ratio of TGF- $\beta 1 / \mathrm{IFN}-\gamma$ mRNA.

Conclusion/interpretation. These findings suggest that combination therapy with sirolimus and tacrolimus prevent autoimmune beta-cell destruction by upregulating expression of the immunoregulatory cytokine, TGF- $\beta 1$ and reducing Th1 cytokines (IFN- $\gamma$ and IL2 ) expressed in the islets. Low-dose sirolimus and tacrolimus combination therapy could warrant consideration for prevention or early treatment of human Type I diabetes. [Diabetologia (2002) 45: 224-230]

Keywords Type I diabetes, NOD mice, sirolimus, tacrolimus, cytokines.
Type I (insulin-dependent) diabetes mellitus is the result of the selective destruction of pancreatic islet beta cells by an autoimmune process. A variety of

Received: 20 August 2001 and in revised form: 29 October 2001

Corresponding author: A. Rabinovitch, 430 Heritage Medical Research Centre, Department of Medicine, University of Alberta, Edmonton, Alberta, Canada, T6G 2S2, e-mail: alex.rabinovitch@ualberta.ca

Abbreviations: NOD, Non-obese diabetic; IFN, interferon; IL, interleukin; TGF, transforming growth factor; BB, biobreeding procedures and therapies that delete, suppress or modulate functions of immune system cells can block the autoimmune response against islet beta cells and prevent beta-cell destruction and Type I diabetes. Immunotherapy might even reverse established diabetes in the NOD mouse, a model of human Type I diabetes [1, 2]. In human Type I diabetes, there is also more potential for the restoration of endogenous insulin secretion and reversal of diabetes than has been assumed. For example, patients receiving the immunosuppressive drug cyclosporine experienced more frequent and longer duration remissions than 
control patients [3]. However, the risk-to-benefit ratio of treating patients with newly diagnosed Type I diabetes with cyclosporine does not justify widespread clinical use.

Identification of effective immunosuppressive agents with lower risk-to-benefit ratios has come mainly from the field of organ transplantation. Recent reports have identified immunosuppressive drug combinations that allow dose reductions of individual drugs and consequently reduction of side effects. The major side effects of the calcineurin inhibitors, cyclosporine and tacrolimus are nephrotoxicity, neurotoxicity, diabetes mellitus and hyperlipaemia. In contrast, combinations of low doses of tacrolimus (FK506), which inhibits IL-2 gene transcription, with sirolimus (rapamycin), which inhibits IL-2 induction of T-cell proliferation [4], provided strong synergistic potentiation of efficacy in animal organ allotransplantation [5-7] and very low rates of rejection of human liver, kidney, and pancreas allografts [8].

Based on these reports, we developed a sirolimustacrolimus combination immunosuppressive therapy, together with a monoclonal antibody against the IL2 receptor, to treat Type I diabetic patients that received human islet allografts. We found that this glucocorticoid-free immunosuppressive regimen for clinical islet allotransplantation in Type I diabetes can result in insulin independence with excellent metabolic control for over 1 year in $80 \%$ of subjects $(12$ of 15) and with no serious side effects $[9,10]$ compared with $14 \%$ for previous islet allotransplantations reported to the islet transplant registry [11].

Human islet allografts transplanted into patients with Type I diabetes elicit two distinct types of immune responses: an allogeneic response to tissue alloantigens and an autoimmune response to islet betacells autoantigens. The purpose of this study was to determine whether sirolimus-tacrolimus combination immunosuppressive therapy can prevent autoimmune beta-cell destruction, in the absence of alloimmunity, and if so, to determine the mechanism of action of this combination therapy.

\section{Materials and methods}

Animals. Female NOD mice, 4 weeks of age, were purchased from Taconic (Germantown, N.Y., USA). The mice were housed and fed under specific pathogen-free conditions and were cared for according to the guidelines of the Canadian Council on Animal Care. Female NOD mice of this colony develop pancreatic islet infiltration by leucocytes beginning at about 4-5 weeks of age. Immunosuppressive drug treatments of NOD mice were begun at 12 weeks of age just before diabetes onset. Another group of female NOD mice were allowed to develop diabetes, and were then treated by daily subcutaneous injections of a 1:1 mix of regular pork and NPH beef insulin (2.0 U/100 g body weight) for 3-6 weeks before receiving transplants of syngeneic islets isolated from female NOD mice, 4 weeks of age.
Diabetes prevention studies. Female NOD mice were treated, from age 12 weeks, with the immunosuppressive drugs sirolimus and tacrolimus. The drugs were given separately or together at doses of $0.1 \mathrm{mg} / \mathrm{kg}$ and $1.0 \mathrm{mg} / \mathrm{kg}$ daily by gavage in medium chain triglycerides oil (Mead Johnsons Nutritionals, Ottawa, Ontario, Canada), and control mice were given the oil vehicle only. Sirolimus (Rapamune) was generously provided by Wyeth-Ayerst Research (Pearl River, N. Y., USA). Tacrolimus (Prograf) was generously provided by Fujisawa Canada (Markham, Ontario, Canada). The mice were monitored daily for diabetes onset by urine testing, using Keto-Diastix (Bayer, Etobicoke, Ontario, Canada). Diabetes onset was diagnosed by the presence of glucosuria $(>6 \mathrm{mmol} / \mathrm{l})$ and ketonuria $(>1.5 \mathrm{mmol} / \mathrm{l})$ and a tail vein blood glucose of $12 \mathrm{mmol} / \mathrm{l}$ or more measured on a glucose meter (Glucometer Elite, Bayer). The mice were killed by sodium pentobarbital overdose after diabetes onset or at the age 35 weeks if still normoglycaemic. Pancreata were removed from diabetic NOD mice treated with vehicle and from all NOD mice that remained normoglycaemic up to 35 weeks of age.

Histologic studies. A portion ( $\sim 10 \%)$ of each pancreas was fixed in $10 \%$ buffered formalin, embedded in paraffin, sectioned at $4.5 \mu \mathrm{m}$, stained with hematoxylin and eosin, and coded slides were examined by light microscopy. Islet inflammation (insulitis) was graded 0 to 3 , according to the extent of intra-islet infiltration by leucocytes: 0 , none; $1,<10 \%$ infiltration; $2,10-50 \%$ infiltration; $3,>50 \%$ infiltration. A mean insulitis score was calculated for each pancreas by dividing the sum of the insulitis scores for individual islets by the number of islets examined.

Insulin assay. The rest $(\sim 90 \%)$ of each pancreas removed from the mice was weighed, minced with fine scissors and incubated in acidified ethanol $(75 \%$ ethanol, $1.5 \% 12 \mathrm{mmol} / \mathrm{l} \mathrm{HCl}$, and $23.5 \% \mathrm{H}_{2} \mathrm{O}$ ) for $18 \mathrm{~h}$ at $4{ }^{\circ} \mathrm{C}$ to extract insulin from the pancreas. The ethanol extracts were diluted in insulin assay buffer and insulin was measured using an RIA kit (Pharmacia, Uppsala, Sweden) and rat insulin as standard.

Sirolimus and tacrolimus assays. Blood concentrations of sirolimus in NOD mice were measured by HPLC-UV assay (Isotechnika, Edmonton, Alberta, Canada) and blood concentrations of tacrolimus were measured by IMX enzyme immunoassay (Abbott, North Chicago, Ill., USA).

Islet transplantation studies. Islets were isolated from 4 week old female NOD mice by collagenase digestion of the pancreas and Ficoll density gradient centrifugation and then hand picked [12]. A total of 500 freshly isolated islets (pooled from about four donor NOD mice) were transplanted under the left renal capsule in each diabetic NOD mouse, according to a previously described procedure [13]. The islet recipient mice were allocated at random to treatment with sirolimus $0.1 \mathrm{mg} /$ $\mathrm{kg}$, tacrolimus $0.1 \mathrm{mg} / \mathrm{kg}$, sirolimus as well as tacrolimus, or vehicle only, given daily by gavage, from the day of islet transplantation. Transplantation was considered successful if the non-fasting blood glucose returned to normal $(<7.0 \mathrm{mmol} / \mathrm{l})$ and remained normal for the first 4 days after transplantation. Urine was monitored daily after transplantation and if glucosuria and ketonuria appeared, then tail vein blood glucose was measured. Graft rejection was diagnosed by return of hyperglycaemia (blood glucose $>12 \mathrm{mmol} / \mathrm{l}$ ) accompanied by glucosuria and ketonuria on two consecutive days. In a second study, diabetic NOD mice received syngeneic islet transplants and treatments with vehicle and with sirolimus and tacrolimus, separately and together. The mice were killed at 12-16 days af- 

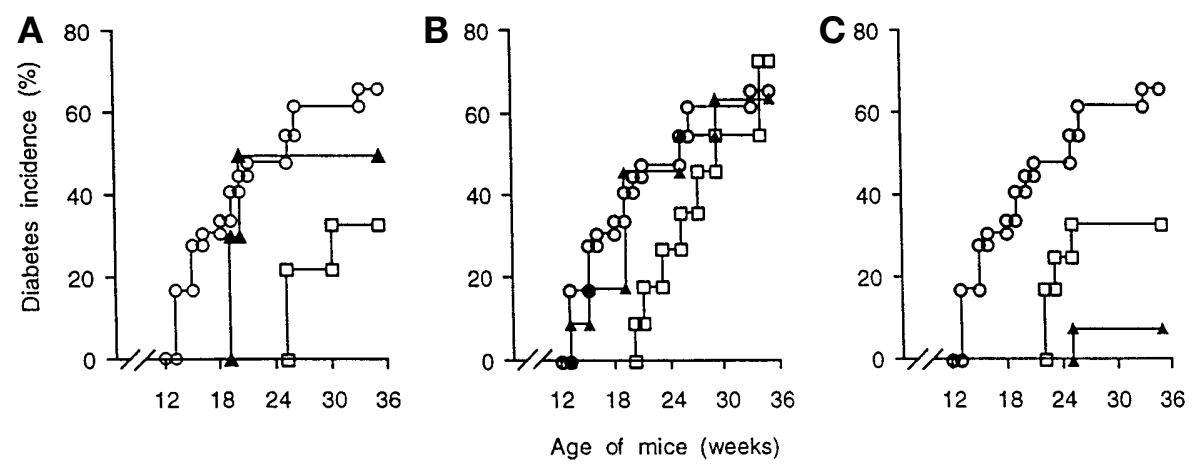

Fig.1(A-C). Diabetes incidence in female NOD mice treated, from age 12 weeks, with sirolimus $(\mathbf{A})$, tacrolimus $(\mathbf{B})$, or sirolimus plus tacrolimus $(\mathbf{C})$. The drugs were given separately or together at doses of $0.1 \mathrm{mg} / \mathrm{kg}$ daily $(\boldsymbol{\Lambda}, n=10-12)$ and $1.0 \mathrm{mg} / \mathrm{kg}$ daily $(\square, n=9-12)$, and control mice were given vehicle only $(\bigcirc, n=17)$. Sirolimus produced a dose-dependent delay in onset and decrease in diabetes incidence at 35 weeks (A). Tacrolimus did not decrease diabetes incidence at 35 weeks (B). Combination of sirolimus and tacrolimus (C), using the low dose of both drugs $(0.1 \mathrm{mg} / \mathrm{kg}$ daily, $\mathbf{A})$ decreased diabetes incidence at 35 weeks the most ( $8 \%, 1$ of 12 mice)

ter transplantations and the islet grafts were removed and studied for cytokine mRNA expression by PCR assays.

PCR analyses. RNA was extracted from islet grafts by a modification of the guanidinium thiocyanate method [14] and cytokine mRNA transcripts were measured in a semi-quantitative RT-PCR assay [15]. cDNA synthesis was carried out on $5 \mu \mathrm{g}$ of total RNA with a Superscript Reverse-Transcriptase Kit (Life Technologies, Burlington, Ontario, Canada), using oligo (deoxythymidine $)_{12-18}$ and Moloney murine leukaemia virus transcriptase $(20 \mathrm{U})$ in a $25-\mu \mathrm{l} \mathrm{vol}$ at $37^{\circ} \mathrm{C}$ for $1.5 \mathrm{~h}$. The reverse transcription product was diluted 1:20,1:100, and 1:500 in sterile $\mathrm{H}_{2} \mathrm{O}$. PCR amplification of cDNA was done on $5 \mu \mathrm{l}$ of each dilution in a $20-\mu \mathrm{l}$ vol containing $80 \mathrm{ng}$ of each primer, $0.25 \mathrm{mmol} / \mathrm{l}$ of each deoxy-NTP, $92.5 \mathrm{KBq}$ of $\left[\alpha{ }^{32} \mathrm{P}\right]$ deoxyCTP (111 MBq/nmol, Du Pont, Mississauga, Ontario, Canada), 2 U of AmpliTaq (Perkin Elmer Cetus, Norwalk, Conn., USA) and $3 \mathrm{mmol} / 1 \mathrm{Mg}^{2+}$. Samples were amplified through 40 cycles at $94^{\circ} \mathrm{C}$ for $20 \mathrm{~s}, 60^{\circ} \mathrm{C}$ for $20 \mathrm{~s}$, and $72^{\circ} \mathrm{C}$ for $30 \mathrm{~s}$ in a Gene Amp PCR System 9600 (Perkin Elmer Cetus). The sequences of the sense and antisense oligonucleotide primers, respectively, were as follows: IL-2, CCTGAGCAGGATGGAGAATTACAG and CTTATGTGTTGTAAGCAGGAGGTAC; IL-4, GTCTCTCGTCACTGACGCACAGAGCTATTG and CATGATGCTCTTTAGGCTTTCCAGGAAGTC; IL-10, AGCTGGACAACATACTGCTAACC and TCATTCATGGCCTTGTAGACAC; IFN- $\gamma$, CGCTACACACTGCATCTTGG and GGCTGGATTCCGGCAACA; TGF- $\beta$, TTGGTATCCAGGGCTCTCC and TGAGTGGCTGTCTTTTGACG; and cyclophilin, GACAGCAGAAAACTTTCGTGC and TCCAGCCACTCAGTCTTGG. The PCR reaction products were electrophoresed on $1.5 \%$ agarose gels and transferred to nylon membranes. Incorporation of ${ }^{32} \mathrm{P}$ in the PCR product bands was measured by phosphor imager analysis (Fujix BAS 1000; Fuji Photo Film, Tokyo, Japan) and expressed as photon-stimulated luminescence for each minute. The values obtained for each cytokine PCR product were normalized as a percentage of cyclophilin PCR product amplified from the same cDNA preparation. All samples compared were amplified in the same PCR run to avoid interassay variation and the final results are the averages from two separate PCR assays.

Statistical analyses. Diabetes incidence data were compared for significant differences by Fisher's exact test. Islet graft survival times (median days after transplantation) were compared for significant differences by the Mann-Whitney rank sum test. All other data are expressed as means \pm SEM values. Differences between groups were analysed by ANOVA with TukeyKramer's multiple comparisons test. A $p$ value of less than 0.05 was considered to be statistically significant.

\section{Results}

Diabetes onset and incidence. Female NOD mice were treated with sirolimus and tacrolimus, separately or together, starting at age 12 weeks (advanced insulitis stage just before diabetes onset). Sirolimus produced a dose dependent delay in onset and decrease in diabetes incidence at 35 weeks (Fig.1A). Diabetes incidence at 35 weeks was $66 \%$ (11 of 17 mice) in vehicle-treated mice, $50 \%$ (5 of 10 mice) in mice treated with sirolimus $0.1 \mathrm{mg} / \mathrm{kg}(p=0.69$, NS vs vehicle), and $33 \%$ ( 3 of 9 mice) in mice treated with sirolimus $1.0 \mathrm{mg} / \mathrm{kg}$ ( $p=0.22$, NS vs vehicle). Tacrolimus did not decrease diabetes incidence at 35 weeks (Fig. 1B). Combination of sirolimus and tacrolimus delayed diabetes onset and reduced diabetes incidence (Fig. 1C). Interestingly, a combination of sirolimus and tacrolimus, using the low dose of both drugs $(0.1 \mathrm{mg} / \mathrm{kg})$ reduced diabetes incidence at 35 weeks the most $(8 \%, 1$ of 12 mice, $p=0.0032$ vs vehicle), compared with $33 \%$ (4 of 12 mice, $p=0.14$, NS vs vehicle) for mice treated with the high dose of both drugs $(1.0 \mathrm{mg} / \mathrm{kg})$, and $66 \%$ (11 of 17 mice) for vehicle-treated mice.

The synergistic effects of low doses of sirolimus and tacrolimus $(0.1 \mathrm{mg} / \mathrm{kg})$ to prevent diabetes development were not due to any drug interactions affecting blood concentrations of the two drugs because blood concentrations of sirolimus were $9.4 \pm 2.3 \mu \mathrm{g} / 1$ in mice treated with sirolimus $0.1 \mathrm{mg} / \mathrm{kg}$ alone $(n=5)$ and $8.5 \pm 1.0 \mu \mathrm{g} / 1$ in mice treated with sirolimus $0.1 \mathrm{mg} / \mathrm{kg}$ plus tacrolimus $0.1 \mathrm{mg} / \mathrm{kg}(n=11)$. 


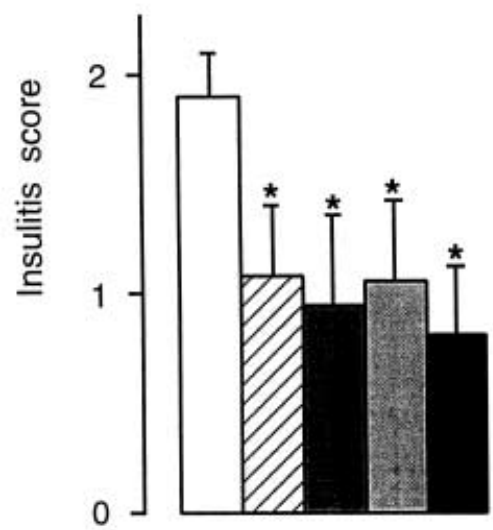

Fig. 2. Insulinitis was significantly less and pancreatic insulin content was significantly greater in female NOD mice that remained normoglycaemic to age 35 weeks after treatment with vehicle (₹, $n=6$ of 17 mice), sirolimus, $0.1 \mathrm{mg} / \mathrm{kg}$ daily (heavily shaded blocks, $n=5$ of 10 mice), tacrolimus, $0.1 \mathrm{mg} / \mathrm{kg}$ daily (lightly shaded blocks, $n=4$ of 11 mice), and sirolimus $0.1 \mathrm{mg} /$ $\mathrm{kg}$ daily plus tacrolimus $0.1 \mathrm{mg} / \mathrm{kg}$ daily $(\boldsymbol{\square}, n=11$ of 12 mice) than in vehicle-treated mice that became diabetic ( $\square, n=11$ of 17 mice) before age 35 weeks. Also, pancreatic insulin content was significantly greater in normoglycaemic mice treated with the combination of sirolimus and tacrolimus than in normoglycaemic mice treated with vehicle. Values are means \pm SEM. ${ }^{*} p<0.05,{ }^{* *} p<0.01$ vs diabetic mice. ${ }^{\dagger} p<0.05$ vs normoglycaemic mice treated with vehicle

Also, blood concentrations of tacrolimus were $3.3 \pm 0.3 \mu \mathrm{g} / \mathrm{l}$ in mice treated with tacrolimus $0.1 \mathrm{mg} /$ $\mathrm{kg}$ alone $(n=4)$ and $3.5 \pm 0.2 \mu \mathrm{g} / \mathrm{l}$ in mice treated with sirolimus $0.1 \mathrm{mg} / \mathrm{kg}$ plus tacrolimus $0.1 \mathrm{mg} / \mathrm{kg}$ $(n=11)$. Blood concentrations of drugs are trough values measured at $24 \mathrm{~h}$ after daily drug administrations from age 12 to 35 weeks. Sirolimus and tacrolimus, given separately or together at a dose of $0.1 \mathrm{mg} / \mathrm{kg}$, did not affect body weights or health of the mice. Also, sirolimus at the higher dose of $1.0 \mathrm{mg} / \mathrm{kg}$ did not affect body weights or health of the mice; however, tacrolimus $1.0 \mathrm{mg} / \mathrm{kg}$, given alone or together with sirolimus, reduced body weight gain in some of the mice.

Pancreatic insulitis and insulin content. Insulitis was significantly less and pancreatic insulin content was significantly greater in female NOD mice that remained normoglycaemic to age 35 weeks after treatment with vehicle, sirolimus $0.1 \mathrm{mg} / \mathrm{kg}$, tacrolimus $0.1 \mathrm{mg} / \mathrm{kg}$, and sirolimus as well as tacrolimus than in vehicletreated mice that became diabetic before 35 weeks of age (Fig. 2). Importantly, pancreatic insulin content was significantly greater in normoglycaemic mice treated with the combination of sirolimus and tacroli-

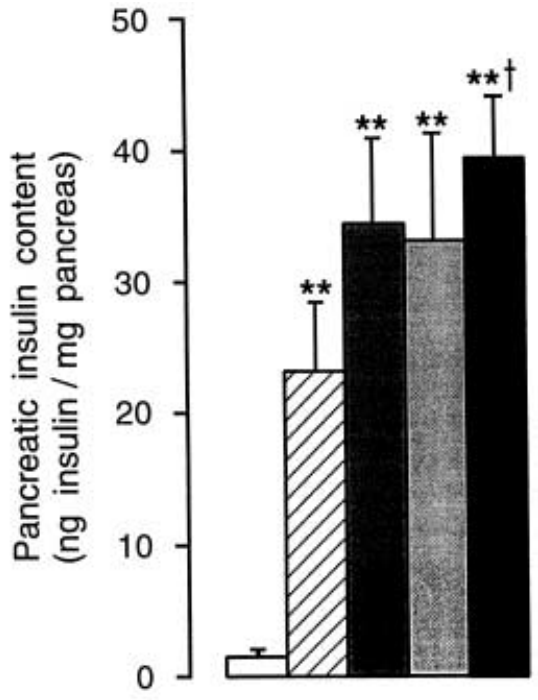

mus $(39.5 \pm 4.6 \mathrm{ng} / \mathrm{mg})$ than in normoglycaemic mice treated with vehicle $(23.1 \pm 5.0 \mathrm{ng} / \mathrm{mg})$ (Fig. 2$)$.

Diabetes recurrence after syngeneic islet transplantation. Syngeneic islet transplantation restored normoglycaemia (blood glucose $<7.0 \mathrm{mmol} / \mathrm{l}$ ) in diabetic NOD mice 8-12 h after transplantation; however, diabetes recurred (blood glucose $>12.0 \mathrm{mmol} / \mathrm{l}$ ) at a median of 13 days (range 7-17) after transplantation in mice treated with vehicle only (Fig.3). Median graft survival (prevention of hyperglycaemia recurrence) in mice treated with tacrolimus was 15 days, not significantly different from that in vehicle-treated mice. In contrast, median graft survival was prolonged to 28 days in mice treated with sirolimus ( $p=0.026$ vs vehicle-treated mice), and to 34 days in mice treated with sirolimus plus tacrolimus ( $p=0.002$ vs vehicle-treated mice).

Cytokine expression in islet grafts and spleens. Cytokine mRNA expressions were measured in islet grafts removed from the left renal subcapsular transplantation site of NOD mice treated with vehicle, sirolimus, tacrolimus, and the combination of drugs at 12-16 days after transplantation. IFN- $\gamma$ mRNA was significantly decreased in grafts from mice treated with either sirolimus, tacrolimus, or the combination of drugs (Fig. 4). In contrast, TGF- $\beta 1$ mRNA expression was significantly increased in islet grafts from mice treated with either sirolimus, tacrolimus, or the combination of drugs. Importantly, the ratio of TGF$\beta 1 / \mathrm{IFN}-\gamma$ mRNA was highest in mice treated with the combination of sirolimus and tacrolimus $(37.2 \pm 7.1)$ compared with $10.8 \pm 3.1$ for mice treated with sirolimus alone and $14.4 \pm 4.7$ for mice treated with tacrolimus alone $(p<0.05$ for effects of drug combination vs either drug alone). IL-2 and IL10 mRNA expression were significantly reduced in mice treated with either tacrolimus alone or the combination of sirolimus and tacrolimus. IL-4 mRNA ex- 


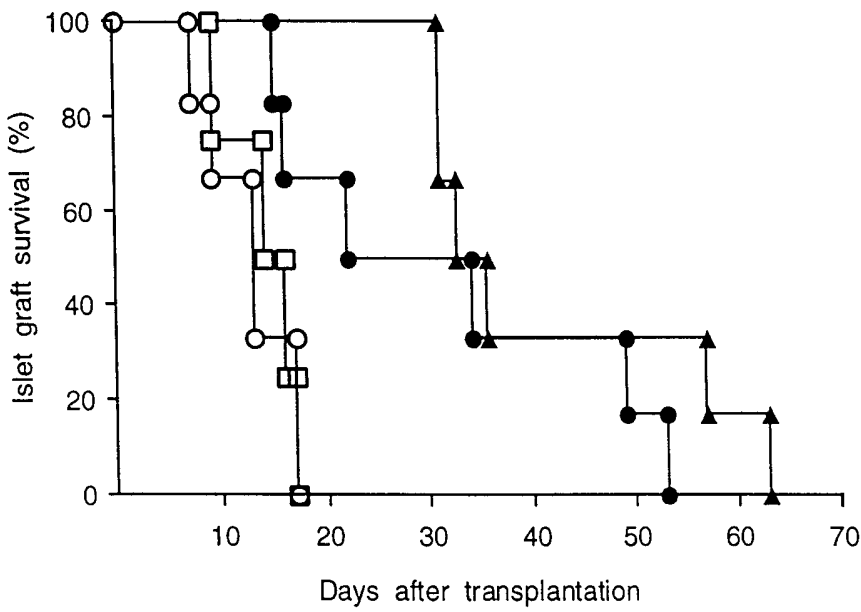

Fig. 3. Sirolimus and the combination of sirolimus and tacrolimus prolong survival of syngeneic islet grafts in NOD mice. Median graft survival was 13 days for mice treated with vehicle $(\bigcirc, n=6), 15$ days for mice treated with tacrolimus $0.1 \mathrm{mg} / \mathrm{kg}$ daily ( $\square, n=4), 28$ days for mice treated with sirolimus $0.1 \mathrm{mg} / \mathrm{kg}$ daily $(\bigcirc, n=6)$, and 34 days for mice treated with sirolimus and tacrolimus $(\boldsymbol{\Lambda}, n=6)$

pression was not significantly different in the different groups of mice. Thus, islet grafts from mice treated with sirolimus plus tacrolimus, which prevented autoimmune diabetes recurrence the longest (Fig. 3), expressed the lowest mRNA contents of Th1-type cytokines (IFN- $\gamma$ and IL-2) and the highest ratio of TGF- $\beta 1 /$ IFN- $\gamma$ mRNA, whereas mRNA contents of other Th2-type cytokines (IL-4 and IL-10) were not increased (Fig. 4).

Cytokine expression patterns in spleens were quite different from those in islet grafts. Thus, IFN- $\gamma$ mRNA expression was not different in spleens from the different groups of mice (Fig. 5); TGF- $\beta 1$ mRNA expression was significantly decreased in spleens of mice treated with sirolimus and tacrolimus, given separately or together; and IL-4 mRNA expression was significantly lower in spleens of mice treated with either immunosuppressive drug.

\section{Discussion}

In this study, we found that combination therapy with low doses of the immunosuppressive drugs, sirolimus and tacrolimus, is synergistic in preventing spontaneous and recurrent autoimmune diabetes in the NOD mouse, a model of human Type I diabetes. These findings are in accord with reports of strong synergistic effects of sirolimus and tacrolimus in prolonging survival of organ allografts in animals [5-7]. Our findings are the first to demonstrate this synergy in autoimmune disease.

Both alloimmune and autoimmune responses depend upon T-cell activation and proliferation, and si- rolimus and tacrolimus inhibit $\mathrm{T}$-cell responses but by different mechanisms. Although both drugs bind to the same cytosolic binding protein, FKBP-12 [16], the tacrolimus-FKBP complex binds to and inhibits calcineurin, thereby blocking gene transcription of cytokines such as IL-2. The sirolimus-FKBP complex on the other hand binds to and inhibits the protein, mammalian target of rapamycin (mTor), thereby blocking cell-proliferation signals induced by growth factors and cytokines such as IL-2 [4, 17]. Therefore, tacrolimus inhibits IL-2 production and early T-cell activation whereas sirolimus has the unique ability to inhibit late T-cell events (ie. IL-2-induced T cell activation). These different mechanisms and sites of inhibition of T-cell activation by tacrolimus and sirolimus explain the synergistic effects of the drugs against allo- and autoimmune responses.

Tacrolimus has previously been reported to reduce diabetes incidence in NOD mice [18] and Biobreeding $(B B)$ rats [19]; however, high doses $(1-2 \mathrm{mg} / \mathrm{kg}$ daily) were used and treatments were started before insulitis development. Furthermore, sirolimus has previously been reported to prevent diabetes in NOD mice [20]. However only doses greater than $0.6 \mathrm{mg} / \mathrm{kg}$ were effective, as in our study where we found that sirolimus $1.0 \mathrm{mg} / \mathrm{kg}$ daily reduced diabetes incidence in NOD mice by $50 \%$ but sirolimus $0.1 \mathrm{mg} /$ $\mathrm{kg}$ daily did not. Importantly, the combination of sirolimus $0.1 \mathrm{mg} / \mathrm{kg}$ and tacrolimus $0.1 \mathrm{mg} / \mathrm{kg}$ almost completely prevented diabetes development in NOD mice but each drug given separately at this low dose had no effects on diabetes incidence. The importance of this strong synergistic effect of sirolimus and tacrolimus is that it was achieved using doses of the drugs that produced blood levels of drugs in the clinical target range desired to prevent toxicity. Indeed, we found that the higher dose of tacrolimus $(1.0 \mathrm{mg} /$ $\mathrm{kg}$ daily) impaired weight gain, as previously reported at this dose of tacrolimus in $B B$ rats [19]. Also, the high dose of tacrolimus, used in combination with sirolimus, was less effective in preventing diabetes than using the lower dose combination of drugs $(0.1 \mathrm{mg} / \mathrm{kg}$ daily $)$. Aside from the toxic effect of the high dose of tacrolimus, we do not have an explanation for why the high dose combination of immunosuppressive drugs was less effective than the low dose combination.

As for mechanisms of the protective effects of sirolimus and tacrolimus against autoimmune betacell destruction, we found that each drug reduced mRNA expression of Th1-type cytokines (IFN- $\gamma$ and IL-2) and increased mRNA expression of the immunoregulatory cytokine, TGF- $\beta 1$ in syngeneic islet grafts, and combination of sirolimus and tacrolimus resulted in the highest ratio of TGF- $\beta 1 / \mathrm{IFN}-\gamma$ mRNA. These effects on cytokine expression were localized to islets and did not occur systemically (in spleens). Our findings in vivo are similar to those re- 



Fig.4. Cytokine mRNA expressions in syngeneic islet grafts from NOD mice treated with vehicle $(\square, n=6)$, sirolimus $0.1 \mathrm{mg} / \mathrm{kg}$ daily (heavily shaded blocks, $n=6$ ), tacrolimus $0.1 \mathrm{mg} / \mathrm{kg}$ daily (lightly shaded blocks, $n=6$ ), and sirolimus plus tacrolimus $(\boldsymbol{\square}, n=8)$ at 12-16 days after islet transplantation. Cytokine mRNA expressions are given as percentages of cyclophilin mRNA. ${ }^{*} p<0.05, * * p<0.01$ vs vehicle-treated mice
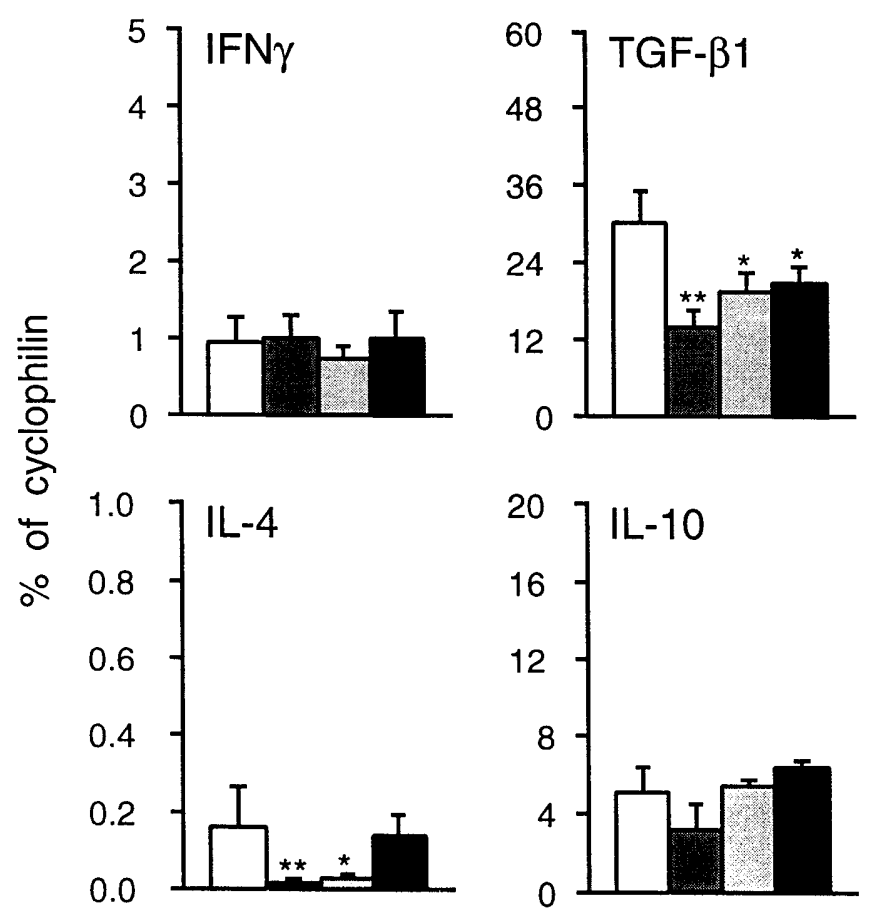

Fig. 5. Cytokine mRNA expressions in spleens from NOD mice transplanted under the renal capsule with syngeneic islets and treated with vehicle $(\square, n=6)$, sirolimus $0.1 \mathrm{mg} / \mathrm{kg}$ daily (heavily shaded blocks, $n=6$ ), tacrolimus $0.1 \mathrm{mg} / \mathrm{kg}$ daily (lightly shaded blocks, $n=6$ ) and sirolimus plus tacrolimus $(\boldsymbol{\square}, n=8)$ at $12-16$ days after islet transplantation. Cytokine mRNA expressions are given as percentages of cyclophilin mRNA. $* p<0.05, * * p<0.01$ vs vehicle-treated mice ported for human peripheral blood lymphocytes activated in vitro [21]. In the latter study, it was found that the combination of sirolimus and tacrolimus produced the greatest increase in TGF- $\beta 1$ and the greatest decrease in IL-2 production by activated lymphocytes, and the author concluded that induction of TGF- $\beta 1$ and inhibition of IL- 2 expression is a common mechanism of the immunosuppressive properties of sirolimus and calcineurin inhibitors [21]. In our study, reduced expression of Th1-type cytokines (IFN- $\gamma$ and IL-2) in islets (eg. by tacrolimus) was not sufficient by itself to prevent autoimmune beta-cell destruction and strong induction of TGF- $\beta 1$ expression (eg. by sirolimus) was also necessary.

Other studies have identified roles for TGF- $\beta 1$ in preventing autoimmune diabetes. TGF- $\beta 1$, expressed transgenically in pancreatic islet beta cells, protected NOD mice from diabetes [22]. In other studies, transgenic expression of TGF- $\beta 1$ in pancreatic islet alpha cells protected NOD mice from diabetes, and the protective action of TGF- $\beta 1$ was related to blocking the cytotoxic effects of diabetogenic effector lymphocytes [23]. Also, TGF- $\beta 1$ somatic gene therapy reduced insulitis and diabetes in cyclophosphamide-accelerated and natural course autoimmune diabetes in NOD mice and pancreatic IL-12 and IFN- $\gamma$ mRNA expression was lower [24]. In addition, we found that TGF- $\beta 1$ production by testicular Sertoli cells is a mechanism by which these cells protect syngeneic islet grafts transplanted into diabetic NOD mice [25]. Similarly, TGF- $\beta 1$ has been implicated as a mediator of the diabetes-preventive effects of isletreactive $\mathrm{CD}^{+}{ }^{+} \mathrm{T}$-cell clones $[26,27]$.

An important finding in this study is that combination therapy with sirolimus and tacrolimus prevented diabetes development in NOD mice at an advanced stage of insulitis, just before diabetes onset. Also, this immunosuppressive drug combination signifi- 
cantly delayed autoimmune diabetes recurrence in diabetic NOD mice transplanted with syngeneic islets. These findings show that low dose sirolimus-tacrolimus combination therapy is effective against an ongoing autoimmune response. Therefore, we suggest that this combined immunosuppressive therapy could warrant cautious consideration for prevention or early treatment of human Type I diabetes. An expanded series of Type I diabetic subjects transplanted with islets alone and treated with a sirolimus-tacrolimus drug combination will allow long-term risks to be defined, thereby clarifying the risk-to-benefit ratio of this therapy for diabetes prevention.

Acknowledgements. This work was supported by a partnership programme grant from the Juvenile Diabetes Research Foundation and the Canadian Institutes of Health Research (1-1999-908), the MacLachlan Fund of the University of Alberta Hospitals and the Muttart Diabetes Research and Training Centre at the University of Alberta. A.M.J. Shapiro is a Clinical Investigator and A. Rabinovitch is a Medical Scientist of the Alberta Heritage Foundation for Medical Research. The authors thank D. Dixon for assistance with islet transplantations, M. Labbe for animal care and D. Glubrecht for assistance with RT-PCR assays.

\section{References}

1. Chatenoud L, Primo J, Bach JF (1997) CD3 antibody-induced dominant self tolerance in overly diabetic NOD mice. J Immunol 158: 2947-2954

2. Ryu S, Kodama S, Ryu K, Schoenfeld DA, Faustman DL (2001) Reversal of established autoimmune diabetes by restoration of endogenous $\beta$ cell function. $\mathrm{J}$ Clin Invest 108: 63-72

3. Mahon JL, Dupre J, Stiller CR (1993) Lessons learned from use of cyclosporine for insulin-dependent diabetes mellitus: the case for immunotherapy for insulin-dependent diabetics having residual insulin secretion. Ann NY Acad Sci 696: 351-363

4. Sehgal S (1998) Rapamune (RAPA, rapamycin, sirolimus). Mechanisms of action: immunosuppressive effect results from blockade of signal transduction and inhibition of cell cycle progression. Clin Biochem 31: 335-340

5. Chen H, Qi S, Xu D et al. (1998) Combined effect of rapamycin and FK506 in prolongation of small bowel graft survival in the mouse. Transplant Proc 30: 2579-2581

6. Vu MD, Qi S, Xu D et al. (1997) Tacrolimus (FK506) and sirolimus (rapamycin) in combination are not antagonistic but produce extended graft survival in cardiac transplantation in the rat. Transplantation 64: 1853-1856

7. Qi S, Xu D, Peng J et al. (2000) Effect of tacrolimus (FK506) and sirolimus (rapamycin) mono- and combination therapy in prolongation of renal allografts survival in the monkey. Transplantation 69: 1275-1283

8. McAlister VC, Gao Z, Peltekian K, Domingues J, Mahalati K, MacDonald AS (2000) Sirolimus-tacrolimus combination immunosuppression. Lancet 355: 376-377

9. Shapiro AMJ, Lakey JRT, Ryan EA et al. (2000) Islet transplantation in seven patients with Type 1 diabetes mellitus using a glucocorticoid-free immunosuppressive regimen. N Engl J Med 343: 230-238
10. Ryan EA, Lakey JRT, Rajotte RV et al. (2001) Clinical outcomes and insulin secretion after islet transplantation with the Edmonton protocol. Diabetes 50: 710-719

11. Brendel MD, Hering BJ, Schultz AO, Bretzel RG (2001) International Islet Transplant Registry Report. University Hospital Giessen, Giessen, pp 1-20

12. Gotoh M, Maki J, Kiyoizumi T, Satomi S, Monaco AP (1985) An improved method for isolation of mouse pancreatic islets. Transplantation 40: 437-438

13. Wang T, Singh B, Warnock G, Rajotte RV (1992) Prevention of recurrence of IDDM in islet-transplanted diabetic NOD mice by adjuvant Immunotherapy. Diabetes 41: 114-117

14. Chirgwin JM, Przybyla AE, MacDonald RJ, Rutter KT (1979) Isolation of biologically active ribonucleic acid from sources enriched in ribonuclease. Biochemistry 18: 5294-5299

15. Rabinovitch A, Suarez-Pinzon WL, Sorensen I, Bleackley RC, Power RF (1995) IFN- $\gamma$ gene expression in pancreatic islet-infiltrating mononuclear cells correlates with autoimmune diabetes in nonobese diabetic mice. J Immunol 154: 4874-4882

16. Kahan BD (1992) Cyclosporin A, FK506, rapamycin: the use of a quantitative analytic tool to discriminate immunosuppressive drug interactions. J Am Soc Nephrol 2[Suppl]: S222-S227

17. Abraham RT, Wiederrecht GJ (1996) Immunopharmacology of rapamycin. Annu Rev Immunol 14: 483-510

18. Miyagawa J, Yamamoto K, Hanafusa T et al. (1990) Preventive effect of a new immunosuppressant FK-506 on insulitis and diabetes in non-obese diabetic mice. Diabetologia 33: 503-505

19. Murase N, Lieberman I, Nalesnik MA et al. (1990) Effect of FK506 on spontaneous diabetes in BB rats. Diabetes 39: $1584-1586$

20. Baeder WL, Sredy J, Sehgal SN, Chang JY, Adams LM (1992) Rapamycin prevents the onset of insulin-dependent diabetes mellitus (IDDM) in NOD mice. Clin Exp Immunol 89: $174-178$

21. Khanna AK (2000) Mechanism of the combination immunosuppressive effects of rapamycin with either cyclosporine or tacrolimus. Transplantation 70: 690-694

22. King C, Davies J, Mueller R et al. (1998) TGF- $\beta 1$ alters APC preference, polarizing islet antigen responses toward a Th2 phenotype. Immunity 8: 601-613

23. Moritani M, Yoshimoto K, Wong SF et al. (1998) Abrogation of autoimmune diabetes in nonobese diabetic mice and protection against effector lymphocytes by transgenic paracrine TGF- $\beta 1$. J Clin Invest 102: 499-506

24. Piccirillo CA, Chang Y, Prud'homme GJ (1998) TGF- $\beta 1$ somatic gene therapy prevents autoimmune disease in nonobese diabetic mice. J Immunol 161: 3950-3956

25. Suarez-Pinzon W, Korbutt GS, Power R, Hooton J, Rajotte RV, Rabinovitch A (2000) Testicular Sertoli cells protect islet $\beta$-cells from autoimmune destruction in NOD mice by a transforming growth factor- $\beta 1$-dependent mechanism. Diabetes 49: 1810-1818

26. Hans H-S, Jun H-S, Utsugi T, Yoon JW (1996) A new type $\mathrm{CD}^{+}$suppressor $\mathrm{T}$ cell completely prevents spontaneous autoimmune diabetes and recurrent diabetes in syngeneic islet-transplanted NOD mice. J Autoimmun 9: 331-339

27. Zekzer D, Wong FS, Wen L et al. (1997) Inhibition of diabetes by an insulin-reactive $\mathrm{CD}^{+} \mathrm{T}$-cell clone in the nonobese diabetic mouse. Diabetes 46: 1124-1132 